\title{
Issues of Reading Habits Among Malaysian Students: School and Home Perceptions
}

\author{
Mohd Fauzan Zulkifli', Muhammad Faizal A. Ghani2*, \\ Norfariza Mohd Radzi ${ }^{3}$,Maszuria A. Ghani ${ }^{4}$
}

\author{
1Faculty of Education, University of Malaya \\ ${ }^{2}$ Faculty of Education, University of Malaya \\ ${ }^{3}$ Faculty of Education, University of Malaya \\ ${ }^{4}$ Institute of Teacher Education, Johor Bahru
}

\begin{abstract}
Keywords:
Student reading habit issues; themes
\end{abstract}

*Correspondence Address:
mdfaizal@um.edu.my

\begin{abstract}
This study aims to analyze issues of reading habits among school students in Malaysia. This study used a qualitative method by conducting semi-structured interviews with school leaders, teachers, and parents in urban and rural areas. Sample selection used the purposive sampling method. Criteria in selecting study participants were position, teaching experience, background related to students' reading habits, and willingness to participate in this study. The findings of this study were analyzed using thematic methods. The analysis of the issues in urban areas resulted in five (5) themes for urban areas, while there were nine (9) themes for rural areas. These themes have been arranged according to the priority of the issue. The themes of issues faced in urban areas consist of (i) Students' Attitudes and Reading Awareness, (ii) Current Reading Programs Need to Be Improved, (iii) Changes in Reading Styles and Technological Developments, (iv) Aspects of Students' Environment That Do Not Support Reading Habits and (v) No Specific Time Allocation for Reading Activities. The results of the analysis of the findings of the study with participants in rural areas consist of (i) Lack of Family Support, (ii) No facilities, (iii) Students' Attitudes and Reading Awareness, (iv) Lack of Interesting Resources and Reading Materials, (v) Limited Reading Resources, (vi) Lack of Teacher Training on Reading Practice Skills, (vii) Aspects of Students' Environment That Do Not Support Reading Habits, (viii) Current Reading Program Need Improvement, (ix) No Clear Guidelines or Profile. The results of this study can serve as a reference, especially at the stakeholder level, such as for the District Education Office, School Administrators, Non-Governmental Organizations (NGOs) as well as for policymakers who may utilize the findings of this study to identify and improve the community and students in Malaysia as a reading community.
\end{abstract}

\section{INTRODUCTION}

Achieving the goal of creating a knowledge society is not an easy endeavor. Furthermore, in the present era, changes occur in every field. These

${ }^{1}$ Clark, C., \& Hawkins, Young people's reading: The importance of home environment and family changes occur relatively rapidly, particularly concerning information, sources of information, and access to such information. ${ }^{1}$ The implication is that people who constantly improve

support: More findings our national survey (London: National Literacy Trust., 2018) 
their knowledge will adapt to these changes for self-success in every field. Individual efforts to improve selfindividual's thinking ability. ${ }^{2}$ Thus, the effort to make reading a habit is an essential objective of education.

However, the reading habits of students worldwide are facing the issue of deterioration. ${ }^{3}$. In Malaysia, the same phenomenon is occurring. Planning and efforts to educate the community to make reading a habit in life are not as simple as expected as they involve various challenging and diverse issues. The question is, what are the issues faced in building the reading habits of Malaysian students today. The reality is that building the reading habits of Malaysian students is faced with various issues and challenges in implementation and planning. Judith Tharumaraj and Noordinfound many issues with students' reading habits in Malaysia involving various aspects of teachers' readiness and reading habits. ${ }^{4}$ Similarly, issues related to the family's socioeconomic background also influence students' reading habits. ${ }^{5}$

The statistics of the Annual Report of the Malaysian Education Development Plan (PPPM) for 2017 show that the effectiveness of students' reading habits in Malaysia is not at a

\footnotetext{
${ }^{2}$ Kutay, V. A survey of the reading habits of Turkish high school students and an examination of the efforts to encourage them to read. Loughborough University,2018.

3 Bashir, I., \& Mattoo, N. H. A study on study habits and academic performance among adolescents (14-19) years. (International Journal of Social Science Tomorrow, 1(5), 2012,

4 Judith Nesamalar Tharumaraj \& Nooreen Noordi, Analysing teachers' reading reading reading habits and teaching strategies for reading skills. Malaysian Journal Of ELT Research, 7 (1), 2011

5 Najeemah Mohd Yusof, Influence of family factors on reading habits and interest among level
}

knowledge are particularly significant with reading habits. According to Kutay, reading activities can improve an reasonable level. ${ }^{6}$ The data of this report are linked to the achievement of Malaysian students in all previous PISA participation which also shows that the country is still far behind compared to the OECD average score. ${ }^{7}$ These statistics also indicate significant differences in reading between urban and rural students. This situation allows researchers to explore the main issues related to Malaysian students' reading habits.

Various changes such as reading trends, generational changes, and environmental factors influence students' reading habits. Changes in students' reading habits indicate reading habits related to and strategies that are appropriate time. ${ }^{8}$ Banou, Kostagiolas, and Olenoglou show that these changes in reading habits and reading behaviors need to be redefined following the shift of reading habits, especially with current technological developments. In addition, developing the reading habits of Malaysian students requires a foundation for implementation that is in line with facts and data. ${ }^{9}$ However, there are still not many studies that identify the issue of

\footnotetext{
2 pupils in national primary schools in Malaysia. Procedia-Social and Behavioral Sciences, 5, 2010.

6 Kementerian Pendidikan Malaysia, Laporan Tahunan 2017 Pelan Pembangunan Pendidikan Malaysia 2013-2025, 2018

${ }^{7}$ Kementerian Pendidikan Malaysia, PISA 2015: programme for international student assessment, 2016

8 Inderjit, S., Reading Trends and Improving Reading Skills among Students in Malaysia. International Journal of Research In Social Sciences, 3(5), 2014

9 Banou, C., Kostagiolas, P. A, \& Olenoglou. The reading behavioral patterns of the Ionian University graduate students: Reading policy of the Greek academic libraries. Library Management, 2008
} 
reading cognitively. ${ }^{10}$ In addition, studies have also shown that reading habits cannot only depend on the role of one party only. Kamalova and Koletvinova have shown that reading problems among students are a problem that needs to be solved jointly by various parties. ${ }^{11}$ This opinion is in line with a study by Olasehinde, Akanmode, Alaiyemola, and Babatunde, showing the importance of the role of various parties in inculcating reading habits in children. ${ }^{12}$ Therefore, this study is essential to help various parties understand which efforts can inculcate reading habits in children. This statement is in line with the view of Banou, Kostagiolas, and Olenoglu that reading policy should be one of the priorities for an academic community. This study aims to identify the issue of students' reading habits in Malaysia. The findings of this study could contribute information to all parties involved in developing reading habits among students. Furthermore, the results of this study help strengthen the goal of creating an informed society.

\section{The Concept of Student Reading Habits}

Obada defines students' reading habits as forming positive behavior and

\footnotetext{
10 Mohamad. Amin Embi, \& Nordin, Determining e-Portfolio Elements in Learning Process Using Fuzzy Delphi Analysis. International Education Studies, 8(9), 2015

11 Kamalova \& Koletvinova, The problem of reading and reading culture improvement of students-bachelors of elementary education in modern high institution. International Journal of Environmental and Science Education, 11(4), 2016

12 Olasehinde, Akanmode, Alaiyemola, \& Babatunde, Promoting the reading culture towards human capital and global development. English Language Teaching, 8(6), 2015
}

acquiring skills that cause an individual to enjoy reading and produce a culture of continuous reading. ${ }^{13}$ In a broader concept, students' reading habits are continuous activities and implemented as a routine in the view of Clark and Hawkins. They state that reading habits are an act that becomes a habit in the daily life of individuals. ${ }^{14}$ In addition, Erdem defines reading habits as habits or patterns of behavior that are learned and reinforced in a conscious way for reading activities that become a habit entering an individual's life. In conclusion, students' reading habits are also predictors of academic achievement. ${ }^{15}$

\section{METHOD}

This study uses a qualitative method using interview sessions. This method was chosen because the researcher could recognize the interviewees' feelings and appreciate the experiences of individuals in society. ${ }^{16}$ In addition, to achieve the objectives of this study, a qualitative approach is seen as more suitable to understanding a phenomenon in-depth, as based on the view of Creswell that the qualitative method is more suitable for the exploration of a phenomenon. ${ }^{17}$ Therefore, this study used the interview

13 Obada, A. M. Reading culture in Nigeria: A librarian's perspective. Ondo: Covena House Publishers, 2019

${ }^{14}$ Clark, C., \& Hawkins, Young people's reading: The importance of home environment and family support: More findings our national survey

(London: National Literacy Trust., 2018)

15 Erdem, A Research on Reading Habits of University Students: (Sample of Ankara University and Erciyes University). Procedia - Social and Behavioral Sciences, 174, 2015

${ }^{16}$ Kvale, S. Doing interviews. Sage, 2008

${ }^{17}$ Creswell, J. W. Educational research: Planning, conducting, and evaluating quantitative and qualitative research ( $3 r d$ ed.). New Jersey: Pearson Prentice Hall, 2008 
method to answer the research question.

The main aspects considered in selecting study participants were position, experience, background related to students' reading habits, and willingness to participate in this study. The sample selection method is based on the purposive sampling method.

Furthermore, the determination of the sample size took into consideration the view of Patton that there are no specific rules in determining the sample size for a qualitative study as long as the researcher can meet the study's objectives. ${ }^{18}$ The selection of small sample size was made based on the views of Onwuegbuzie and Collins to avoid the possible difficulties of data analysis. ${ }^{19}$ Thus, this study involved nine study participants, as shown in Table 1 below, which shows the categories of study participants based on job background.

Table 1. Selection of Study Participants Based on Job Background

\begin{tabular}{lc}
\hline \multicolumn{1}{c}{$\begin{array}{c}\text { Category of study } \\
\text { participants }\end{array}$} & $\begin{array}{c}\text { Number of } \\
\text { participants }\end{array}$ \\
\hline School Leaders & 3 \\
Teachers & 3 \\
Parents & 3 \\
Total & $\mathbf{9}$ \\
\hline
\end{tabular}

\footnotetext{
${ }^{18}$ Patton, M.Q. Qualitative research and evaluation methods (2nd ed.). Newbury Park, CA: Sage, 1990

19 Onwuegbuzie, A. J., \& Collins. A typology of mixed methods sampling designs in social science research. The Qualitative Report, 12 (2), 2007

20 Yin, R.K. Case study research: Design and methods(3 ${ }^{\text {rd }}$. Newbury Park, CA : Sage, 2014

21 Holland, M. Analysing and interpreting the data. Dalam C. Daymond dan I. Holloway. Qualitative Research Methods in Public Relations and Marketing Communications, 2002
}

This study used a semistructured interview protocol. An expert review validated the interview instrument protocol. The reliability of this study instrument was enhanced by using the same set of interview protocols for each session, involving different respondents, locations, and backgrounds, as suggested by Yin. ${ }^{20}$

The qualitative data of this study were analyzed using thematic methods. According to Holland 21 there is no standard level or rule for every researcher for qualitative research. Similarly, Cohen, Manion, and Morrison also express no agreement on qualitative data analysis methods among qualitative researchers. ${ }^{22}$ Thus, for the qualitative data analysis of this study, the researcher chose an approach based on the views of Miles and Huberman, which involve procedures such as transcribing interview data and then reducing the data using thematic analysis. ${ }^{23}$ This stage reduces the interview data and starts with reading the manually encrypted data. The critical information in the data is compiled and then interpreted for the study analysis report. The researcher also reduced the data by coding the data related to the research question, as suggested by Holland. ${ }^{24}$ Next, the data were filtered and sorted into category groups and sub-categories according to theme codes. The theme of this study is

\footnotetext{
22 Cohen, L., Manion, L., \& Morrison, K. Research method in education (5th.). London: Routledge Palmer, 2000

23 Miles, M. B., \& Huberman, Qualitative data analysis: An expanded sourcebook (2nd ed.). Thousand Oaks: Sage Publications, 1994

${ }^{24}$ Holland, M. (2002). Analyzing and interpreting the data. Dalam C. Daymond dan I. Holloway. Qualitative Research Methods in Public Relations and Marketing Communications, 2002
} 
built based on the findings of previous studies and the study's findings. Finally, themes of the study were arranged according to the priority and frequency of theme statements obtained from the analysis of the interview data collected.

\section{FINDINGS}

\section{Participant Profiles}

Selecting Participants of this study was by purposive sampling. They consisted of nine (9) school leaders with over five years' experience, teachers with experience with students' reading practice over five (5) years, and parents of students who had received NILAM awards shown in Table 2.

Table 2. Participant profiles by category and location

\begin{tabular}{ll}
\hline \multicolumn{1}{c}{ Category } & \multicolumn{1}{c}{ Location/Profile } \\
\hline School Leaders & 2 urban \\
& schools, \\
& 1 rural school \\
Guru & 1 urban school, \\
& 2 rural schools \\
Ibu Bapa & 1 rural school \\
& 1 urban school \\
& 1 schooling experience \\
& abroad \\
\hline
\end{tabular}

The study participants involved were school leaders who had the position of deputy principals, Head of Department, and committee heads and who had served for more than ten years. The teacher category consists of language teachers, Resource and Media Center Teachers, and innovative teachers who have more than five years of experience in the reading practice of school children. For the parent category, selection criteria included having a child who had received a NILAM award, and one of them also had experienced schooling abroad. The study also considered participants' local, either urban, or rural school areas. A summary of the codes and profiles of each participant in this study is shown in the following table.

Table 3. Summary of Interview Participant Code

\begin{tabular}{lll}
\hline Code & Category & Location \\
\hline I1 & Teacher & Rural \\
I2 & Teacher & Urban \\
I3 & Teacher & Urban \\
I4 & School Leader & Urban \\
I5 & School Leader & Urban \\
I6 & School Leader & Rural \\
I7 & Parent & Rural \\
I8 & Parent & Urban \\
I9 & Parent & Urban \\
\hline
\end{tabular}

\section{Issues of the Effectiveness of Reading Habits of School Children in Urban Areas}

To meet the objectives of this study, researchers conducted interviews to identify issues and challenges faced by study participants in urban areas that were analyzed thematically. The researchers identified the following themes:

\section{(a) Theme: Students Attitudes and Reading Awareness}

The main issue stated by participant I3 (teachers) was the attitude of students, such as limited reading resources among students, who tend to engage only in academic reading for examination purposes as well as indicating a lazy attitude to reading as follows:

The main issue is their actual attitude. The attitude of students (I3, 64-65)

Students are also said to suggest that where they have no awareness of the 
importance of having effective reading habits, as the following statement by participant I3:

It is also possible that they do not understand the importance of reading. Because It is something that distracts them from a mobile phone. $(13,98-100)$

School leaders in the urban areas also agree with the statement that most students still do not have an awareness of the importance of having reading habits, as stated by the following by participant I4:

In this reading issue, a percentage of students do not have that interest in themselves. There are many reasons why they do not have that Awareness (I4, 15-19)

Students' attitude in the urban areas towards reading habits depends on their own needs. This means that they will only read if there is a need for them to do the activity as stated by the following by participant I5:

I do not see the attitude of students towards this reading habit. Nevertheless, when it comes time for the exam, it is different. Also, a reference book, right? (I5, 23-27)

For urban parents, their children's attitudes towards reading are a significant challenge. Participant I8 views students' attitudes as wildly diverse and challenging to predict. To form their attitude towards reading habits requires an extended period as suggested by the following statement:

The boys now are too difficult for me to predict their attitude. Especially

\section{if we want to see their attitude} towards reading. $(18,13-15)$

In addition, urban parents also shared the view that students' attitudes towards reading habits are influenced by the attitudes of the community and their own families, as stated by participant I9:

Their attitude will follow what we do. The problem now is that we do not have such an attitude towards reading the way they need $(19,23-$ 26)

\section{(b) Theme: Current Reading Program Needs Improvement}

Based on the interviews conducted, teacher participants and school leaders agreed that the current reading program is one of the issues or challenges to developing the reading habits of students in urban areas. Participant I3 stated that the current reading program used by the school has not been successful in increasing the effectiveness of students' reading habits and needs improvement as per the following statement:

I think evaluating the habit of reading using the number of books may not suit the current situation. There must be another profile, meaning another method (I3,86-92)

School leaders I4 and I5 also stated that the current reading program needs improvement in enhancing the effectiveness of students' reading habits in urban areas that are appropriate to the current situation, as indicated by the following statements: 
What is more, I saw this NILAM done at school. I just saw that we wanted to run it. We just wanted to see the number of books that students read and how many pages students read (14,36-40)

It is just that the NILAM is more for reporting. It would be good if there is an improvement in this NILAM with other programs. (I5, 81-84)

Similarly, parents who view the existing reading program see it as ineffective because the method used may not have a fun mechanism to improve students' reading habits, as in the following statement:

I see that NILAM's program is good, but his methods cannot help us improve the reading habits of these children. (I8, 30-36)

In addition, parents also view the current reading program looking only at the quantity and immediate benefits as opposed it can make students' reading habits long-lasting as the following statement:

We do not just want to see beautiful numbers or immediate effects. If we can, we want the habit of reading to be something that lasts until they are old. $(19,56-58)$

\section{(c) Theme: Students' Environment Does Not Support Reading Habits}

The student environment, such as the influence of parents who do not support the effectiveness of students' reading habits in urban areas, was also identified as among the issues raised as stated by participant I3:
Maybe it is also a factor from people around. There is a possibility that the parents themselves do not read, so the children do not read either. (I3, 66-68)

The diversity of students' family backgrounds, especially those related to financial ability in providing a reading environment, are also among the issues faced as stated by participant I4:

I think this family background also plays a role in making a boy read. Not everyone comes from a happy family (I4, 36-38)

School leader I5 also mentions that family and community support factors are among the challenges faced in the following statement:

There are also other possibilities such as no motivation from parents or family. (I5, 63-64)

\section{(d) Theme: Changing Reading Styles and Current Technological Developments}

An urban school leader (I4) stated the issue of significant changes to the reading style of the current generation, which is more diverse, requires a new approach to produce an effect on students' reading habits as follows:

If we look at the way students read the world now. There are many ways, and there are many styles to read (I4,20-21)

Nevertheless, now times have changed. Reading has become extensive. Reading that can also be from internet materials, digital books. (I4, 32-34) 
Similarly, the opinion of participant I5, who stated that students in urban areas face the issue of competition of student interests with the development of current technology and new media that affect their reading habits as in the following statement:

In the urban area here, the most important thing is the competition with the phone, like playing games (I5, 56-57)

The following parents also supported this statement:

In this age of information explosion, they cannot get it all from one source. We must pay close attention to all these things (I8, 97-100)

Maybe the information they are looking for is there. There are more kinds of Youtube and Facebook. We do not know. For me, that is the challenge that we face. $(19,56-60)$

\section{(e) Theme: No Specific Time Allocation For Reading Activities}

For urban school leader I4, the issue of no specific time allocation for reading activities is a matter that has to be faced because the daily activities of students are filled with other things as the following statement:

In my school the main issue is time. $(I 4,85)$

The issue of lack of specific time for reading activities becomes a hindrance to reading habits, such as in the following statement by I8:
It is time for our schools to have an opportunity or time for students to read. Their time is very packed from morning to night. (18, 67-70)

Summaries of the themes of the issue of students' reading habits in urban areas are arranged in order of priority based on the frequency of theme codes as a result of the analysis shown as follows in table 4:

Table 4. Frequency of Theme Statements on Students' Reading Habits Issues in Urban Areas

\begin{tabular}{|c|c|c|c|c|c|c|}
\hline \multirow[t]{2}{*}{ THEMES } & \multicolumn{5}{|c|}{ PARTICIPANT } & \multirow[t]{2}{*}{ FREQUENCY } \\
\hline & I3 & 14 & 15 & 18 & 19 & \\
\hline $\begin{array}{l}\text { Students } \\
\text { Attitudes and } \\
\text { Reading } \\
\text { Awareness }\end{array}$ & 3 & 1 & 1 & 1 & 1 & 7 \\
\hline $\begin{array}{l}\text { Current } \\
\text { Reading } \\
\text { Program } \\
\text { Needs } \\
\text { Improvement }\end{array}$ & 1 & 1 & 1 & 1 & 1 & 5 \\
\hline $\begin{array}{l}\text { Changing } \\
\text { Reading } \\
\text { Styles and } \\
\text { Current } \\
\text { Technological } \\
\text { Developments }\end{array}$ & - & 2 & 1 & 1 & 1 & 5 \\
\hline $\begin{array}{l}\text { Students' } \\
\text { Environment } \\
\text { That Does Not } \\
\text { Support } \\
\text { Reading } \\
\text { Habits }\end{array}$ & 1 & 1 & 1 & - & - & 3 \\
\hline $\begin{array}{l}\text { No Specific } \\
\text { Time } \\
\text { Allocation For } \\
\text { Reading } \\
\text { Activities }\end{array}$ & - & 1 & - & 1 & - & 2 \\
\hline
\end{tabular}

\section{Issues of the Effectiveness of Reading Habits of School Children in Rural Areas}

Issues and challenges expressed by participants in rural areas were analyzed and identified as expressing the following themes

(a) Theme: Lack of Family Support 
Lack of family support due to economic and environmental conditions affects the effectiveness of students' reading habits in rural areas and is a relatively important issue according to participants I1 and I2:

The second issue is the role of parents. Some parents do not care about their children's condition at school. Which means they handed over one hundred percent of everything to the teacher. (I1,6672)

That is hard, I mean in terms of parental contribution funds. All students liked it but could not get full support (I1,83-86)

Most parents are village workers. It is just that it is hard to engage parents $(12,74-75)$

That awareness should come from the home. Again, before entering school, they were at home $(12,143-$ 144)

But if there is no enforcement from the parents at home, then it will not be a reading culture (I2,232233)

This issue was also discussed by rural leader I6, where the surrounding conditions and family life of students in rural areas prevented him from getting support from students' mothers in shaping the effectiveness of reading habits as indicated in the following:

Another issue is that this student himself does not have the opportunity to read. When he is from the countryside, the family is impoverished. Usually, the mother and father both work, so the rest is always up to him. (I6, 64-66)

\section{(b) Theme: No facilities}

Lack of access to other reading resources such as public libraries or digital infostructure is a critical issue in rural areas, preventing them from physical reading or digital reading as indicated by participants I 1 and I2:

\section{We should take advantage of} gadgets like online reading. Nevertheless, there are also challenges to the school's internet network. How do I say this? Here, if it rains, there is no wifi in the school (I1, 116-118)

The village does not have a library. So in school alone, there is a library for their only reading source. (12,158-159)

I suppose that here access is
minimal. This school, which only
has a computer lab, only has nine
PCs that can be used. There are 40
students in one class. (I2, 208-
210)

For rural areas, participant I2 reported that access to reading materials was almost non -existent as per the following statement:

As I said before, just in this village there is no library, no stationery store or bookstore so I can say that access to books is almost nonexistent $(12,168-170)$

The same issue was also expressed by parents of students in rural areas as follows: 
Facilities for these students are fundamental to me. Facilities at the school are just the basics as far as books in the library are concerned (I7, 102-104)

\section{(c) Theme: Student Attitudes and Reading Awareness}

As well as the issues faced by teachers in urban areas, experienced teachers in rural areas also considered students' attitudes and awareness of reading habits to be the main issues and challenges faced as the following statements of participants I1 and I2 indicate:

First of all, the attitude of rural students. Some students have a lazy attitude (I1,66-67)

The same goes for the views of participant I2

I think the main issue is Awareness which is the awareness of reading. When there is no awareness, then there is no readiness. $(12,140-141)$

I see their activities are more about playing. It feels more like a lack of interest in reading than the issue of the source $(12,199-201)$

The same issue was also mentioned by the parents of students in rural areas facing the issue where the attitude of students as the main factor in the following statement of participant I7:

To me, the most important thing is his attitude. Be worried, be upset if the child does not read (I7, 42-43) (d) Theme: Lack of Interesting Resources and Reading Material

Teachers in rural areas stated that one of the main challenges for students in rural areas is the lack of reading material resources due to demographic and access factors, as the following statement indicates:

Many students here only go out to the city a few times a year, so if you want to buy books for reading material, what is it like. I think the issue of lack of resources can be said to be our main challenge here as well (I1, 77-79)

The same goes for the views of the following teacher:

We do not have many students, so allocation will follow the number of students. Our books are old and uninteresting books (I2, 59-60)

For rural leaders I6, providing exciting reading resources to students is a challenge shaping students' reading habits.

If there is an issue for me in rural areas, the student does not have enough material. There is a lot of reading material but exciting reading material that does not exist (I6, 58-59)

This exciting reading issue is the concern of all parties. It is not limited to the teacher (I6, 78-79)

\section{(e) Theme: Limited Reading Sources}

To increase the effectiveness of reading habits, participants $\mathrm{I} 1$ and $\mathrm{I} 2$ stated that students in rural areas face limited reading resources even for the 
materials available in the library and school resource center. The same goes for the resources available in their homes and village areas, as the following statements indicate:

Like us here, the school resources are all quite limited. Like wanting to buy books, everyone needs a big budget. (I1,27-28)

As I said, the school lacks material. So we need extras. (I1, 112-113)

Yes. The only problem is the number of books is not enough. There are still some that have to be shared (I2,114-115)

\section{(f) Theme: Teachers Lack Training on Reading Practice Skills}

Teachers in rural areas view the training aspect of the development of reading habits as an obstacle and an issue for them, as stated by participants I1and I2:

Not all teachers know how to build Teachers who take courses will probably know (I1, 98-101)

If anyone knows what kind of reading technique is needed, most are language teachers. So it would be better if all teachers could have such training $(12,103-105)$

Leaders in rural areas also face issues where teachers in their schools still lack the skills to increase the effectiveness of students' reading habits, as stated by participant I6:

If this teacher is searching for new knowledge, he is exposed, but if he is not, he is not. $(16,89-90)$

\section{(g) Theme: Students' Environment That Does Not Support Reading Habits}

Participant I2 argued that for students in rural areas, an environment that does not support reading habits is also an issue faced by them in shaping the effectiveness of reading habits, as in the following statement:

\section{Parents have all kinds of backgrounds. Here, most villagers work, so we understand that they cannot afford things. (I2,44-45)}

In addition, school leaders in rural areas also stated that students' environment does not support students' reading habits, because of the lack of access to reading materials, as in the following opinion:

I think the children in the rural areas here have almost no access to reading materials, so how can they be said to have the habit of reading. (I6, 20-22)

Rural parents also support this statement:

I believe that the environment of our students here is mostly not a reading environment. (17, 33-34)

\section{(h) Theme: Current Reading Program Needs Improvement}

As in urban areas, teachers in rural schools also addressed the issue of current reading programs are still not able to form effective habits as stated by participant I1:

As of now, the NILAM's data does not seem to reflect the real 
situation. It is more like just wanting a report. (I1,96-97)

In addition, national-minded teachers still do not have a specific program to develop students' reading habits, as in the following statement.

I do not think we have a program that focuses on these students having reading habits as in foreign countries (I2, 30-33)

\section{(i) Theme: No Clear Guidelines or Profiles}

Teachers in rural areas very much feel the need for clear guidelines because they face the issue of no guidelines that can be referred to in conducting a school reading practice program as stated by I1:

\section{If there are guidelines or procedures related to this reading practice, I think it is very appropriate. (I1,88-89)}

The same issue was also expressed by the parents of students who had the issue of lack of references or guidelines or profiles on reading practices implemented in school to continue at home as stated by participant I7:

It is also good if there is a profile on how to do the digital reading. So parents can cooperate with the school on how to handle the reading. $(I 7,54-56)$

Summaries of the themes of the issue of reading habits of students in rural areas are arranged in order of priority based on the frequency of theme codes resulting from the analysis, as shown in table 5 .

\begin{tabular}{|c|c|c|c|c|c|}
\hline \multirow[t]{2}{*}{ THEMES } & \multicolumn{4}{|c|}{ PARTICIPANT } & \multirow{2}{*}{ FREQUENCY } \\
\hline & I1 & 12 & I6 & 17 & \\
\hline $\begin{array}{l}\text { Students } \\
\text { Attitudes and } \\
\text { Reading } \\
\text { Awareness }\end{array}$ & 2 & 3 & 1 & 1 & 6 \\
\hline No facilities & 1 & 3 & - & 1 & 5 \\
\hline $\begin{array}{l}\text { Students' } \\
\text { Environment } \\
\text { Does Not } \\
\text { Support } \\
\text { Reading Habits }\end{array}$ & 1 & 2 & - & 1 & 4 \\
\hline $\begin{array}{l}\text { Lack of } \\
\text { Interesting } \\
\text { Resources and } \\
\text { Reading } \\
\text { Material }\end{array}$ & 1 & 1 & 2 & - & 4 \\
\hline $\begin{array}{l}\text { Limited } \\
\text { Reading } \\
\text { Sources }\end{array}$ & 3 & 1 & - & - & 4 \\
\hline $\begin{array}{l}\text { Teachers Lack } \\
\text { Training on } \\
\text { Reading } \\
\text { Practice Skills }\end{array}$ & 1 & 1 & 1 & - & 3 \\
\hline $\begin{array}{l}\text { Students' } \\
\text { Environment } \\
\text { That Does Not } \\
\text { Support } \\
\text { Reading Habits }\end{array}$ & - & 1 & 1 & 1 & 3 \\
\hline $\begin{array}{l}\text { Current } \\
\text { Reading } \\
\text { Program } \\
\text { Needs } \\
\text { Improvement }\end{array}$ & 1 & 1 & - & - & 2 \\
\hline $\begin{array}{l}\text { No Clear } \\
\text { Guidelines or } \\
\text { Profiles }\end{array}$ & 1 & - & - & 1 & 2 \\
\hline
\end{tabular}

Table 5. Frequency of Theme Statements on Students' Reading Habits Issues in Rural Areas

\section{RESULT AND DISCUSSION}

In developing reading habits, students have issues and challenges of various sorts. The main issues faced in urban and rural areas are different but have similarities in several aspects. This study aims to analyze the issues of reading habits of students in Malaysia that involve exploration in urban and rural areas. The analysis of issues in urban and rural areas has resulted in five (5) themes for urban areas and nine (9) themes in rural areas. The themes are arranged in order of priority.

The themes of issues faced in urban areas consist of (i) Students' Attitudes and Reading Awareness, (ii) Current Reading Programs Need to Be 
Improved, (iii) Changes in Reading Styles and Current Technological Developments, (iv) Students' Environment That Does Not Support Reading Habits and (v) No Specific Time Allocation for Reading Activities.

The results of the analysis of participants in rural areas consist (i) Lack of Family Support, (ii) No facilities, (iii) Students' Attitude and Reading Awareness, (iv) Lack of Interesting Resources and Reading Materials, (v) Limited Reading Resources (vi) Teachers Lack Training on Reading Practice Skills (vii) Studentls' Environment That Does Not Support Reading Habits (viii) Current Reading Program Needs Improvement (ix) No Clear Guidelines or Profile.

For urban areas, students' lack of interest in reading habits is one of the issues faced. The tendency of students to read materials depending only on their needs, such as to do assignments or take exams For parents, the current attitude of students, from which it is difficult to predict the direction of their tendencies, is an obstacle to the development of reading habits. Students also lack awareness of the need to have reading habits. Parents also stated that family and community factors influence negative attitudes towards reading habits in urban areas. Due to these factors, this issue has become so important as the findings of Lau's study that the decline in reading motivation results from a sudden change in students' reading experience. ${ }^{25}$

\footnotetext{
25 Lau, K. Within-year changes in Chinese secondary school students ' perceived reading instruction and intrinsic reading motivation, 2014

26 Loh, C. E. Building a Reading Culture in a Singapore School: Identifying Spaces for Change Through a Socio-spatial Approach. Changing
}

The study also found that the current reading program conducted in schools is considered unable to develop students' reading habits are also raised by interviewees in urban areas. School leaders and teachers agree that reading programs such as NILAM only report the number of student readings compared to the effectiveness values resulting from reading activities. This is in line with the results of a study by Loh. ${ }^{26}$ In this aspect of the issue, parents feel that an improvement should be made to the current reading program, which is more like reporting reading quantity than effectiveness. The existing programs do not have a fun reading activity mechanism that allows students to develop long-lasting reading habits.

The development of students' reading habits also faces issues related to changes in current reading styles. Namely, students are more inclined to read on various platforms, including digital mediums. This phenomenon makes students face the competition of interest in developing technology, which is more interesting than reading. This reduces students' reading habits to a lower practical level. These findings align with Kamalova and Koletvinova's study, showing that young people have gradually changed their perceptions of information. ${ }^{27}$ These changes also have an impact or effect on the effectiveness of one's reading habits. This means that short messages, hyperlinks, or virtual clips have replaced existing reading practices or habits. However, parents

English: Studies in Culture and Education, 22(2), 2015

27 Kamalova \& Koletvinova, The problem of reading and reading culture improvement of students-bachelors of elementary education in modern high institution. International Journal of Environmental and Science Education, 11(4), 2016 
believe that this competition should be accepted as a reality of student life now.

Finally, students in urban areas are faced with not having adequate time opportunities to perform reading activities. This is because their daily time is filled with activities. School leaders and parents view the absence of specific time in the timetable for reading activities as an issue that needs to be researched and addressed. They argue that time at school can be utilized by allocating a particular time for students to perform fun reading activities and, in turn, build lasting habits for them.

The analysis results found that there are more issues faced in rural areas compared to urban areas. The lack of family support in building students' reading habits is the most critical issue due to environmental and economic factors. In this aspect, the role of schools and teachers is seen as the most important that can help improve this situation. These issues reinforce the findings of a study by Pandian, Anak Mikeng, Mikal, \& Dawn Kundrata that found that families play an essential role in children's reading development, including their role in determining the type and content appropriate to the child's level and needs as well as full support, as opposed to student reading assignments given by the school ${ }^{28}$

In addition, the main issue faced in rural areas is the lack of facilities for reading activities such as library facilities and infostructure. Students in rural areas rely only on resources from the limited facilities available at the school to carry out reading activities. The school and parents stated that the

\footnotetext{
${ }^{28}$ Pandian, Mikal, E., \& Dawn Kundrata, Reading with Mom: Reading Habits among Rural Readers in Sarawak. International Journal of Asian Social Science, 10(1), 2020

${ }^{29}$ Chotitham, S., \& Wongwanich, S. The Reading Attitude Measurement for Enhancing Elementary
}

facilities available in the students' environment are only basic facilities, which cannot help develop reading habits in their area. This statement aligns with Chotitham and Wongwanich's study, which identified the developmental component (to improve academic achievement) and the benefit component derived from reading habits as factors in building students' reading habits. ${ }^{29}$

Furthermore, as with those in urban areas, the same issue is also faced in rural areas, where students' attitudes toward and awareness of the importance of reading habits are still low. Teachers face difficulties in instilling awareness of the importance of reading due to the attitudes of rural students. The results of this study support the findings of Annamalai and Muniandy's study. There are other ways to learn new things than reading because students find reading boring and unmotivating. ${ }^{30}$ However, the attitude factor of students in rural areas is more due to competition with activities that are closely related to their environment, such as playing with friends in their free time, than with having the effectiveness of reading habits.

Demographic factors have led to the lack of resources and reading materials of interest to rural areas. Most of them do not have access to resources to obtain exciting, and up-to-date reading material are minimal. In addition, the school also faces the issue of difficulty in obtaining interesting reading resources due to funding factors. This is because the allocation for

School Students 'Achievement. Procedia - Social and Behavioral Sciences, 2014

${ }^{30}$ Annamalai, S., \& Muniandy, Reading Habit and Attitude among Malaysian Polytechnic Students. International Online Journal of Educational Sciences, 5(1), 2013 
reading materials (PCG) is based on the number of students in rural areas, usually very limited. The results of this study are in line with the findings of a study that showed that students who have a high self-concept as a reader are also able to apply reading comprehension strategies. ${ }^{31}$ Overall, students found reading very enjoyable and were more interested in collaborative reading activities and visual books.

In rural areas, resource issues are also faced in building students' reading habits due to the economy and the environment. Most student families in this area focus more on other basic things than buying reading material resources. This stated issue is in line with the results of a study that the socioeconomic background of the student's family also influences students' reading habits. $^{32}$ This issue of limited resources is also faced by schools where their libraries and resource centers do not have exciting and up-to-date reading materials to encourage interest in reading.

In contrast to urban areas, most teachers and school leaders in rural areas stated that they lacked training related to improving students' reading habits. They also stated that teachers in these areas are still lagging in reading skills such as effective reading techniques and somewhat backward in

31 Mujan Yusuf, K., Sigan John, D., Dawn Kundrata, K., \& Pandian, (2019). Value and SelfConcept: A Study on Reading Habits among Primary School Students in Sarawak. International Journal of Asian Social Science, 9(12), 2019

32 Najeemah Mohd Yusof, Influence of family factors on reading habits and interest among level 2 pupils in national primary schools in Malaysia. Procedia-Social and Behavioral Sciences, 5, 2010. aspects of the latest technology. Teachers in rural areas also stated that they are still less exposed to the development of current training such as digital reading methods when compared to teachers in urban areas. The same issue was also stated in a study by Zuridah Hanim Akhir, Mohd Hasani Dali \& Khaliza Saidin, which clearly shows that this component needs to be given serious attention by school leaders to enable the reading program development process to be implemented more effectively. ${ }^{33}$

The next issue is related to the environment of students in rural areas, which does not support the development of students' reading habits. The students' environment does not reflect reading habits because their activities are just routine activities. This factor is due to environmental conditions such as being far from access to reading materials and academic facilities that can help build reading habits. This issue is also supported through studies by Mujan Yusuf, Sigan John, Dawn Kundrata and Pandian. ${ }^{34}$ Components such as providing opportunities for students to choose the reading that suits their interests and level also dramatically help to improve reading habits. In addition, the school component also needs to use technology to motivate young readers and the

\footnotetext{
33 Zuridah Hanim Akhir, Mohd Hasani Dali, \& Khaliza Saidin. Faktor yang mempengaruhi peranan pengetua dalam meningkatkan amalan membaca menerusi program NILAM. Journal of Advanced Research in Social and Behavioural Sciences Journal, 1(1), 2017

34 Mujan Yusuf, K., Sigan John, D., Dawn Kundrata, K., \& Pandian, (2019). Value and SelfConcept: A Study on Reading Habits among Primary School Students in Sarawak. International Journal of Asian Social Science, 9(12), 2019
} 
family support component, especially by parents.

Teachers in rural areas stated that they face issues with the current reading program, which does not favor the situation of students in their area. This is because it is pretty difficult for a program that looks only at the reading material. After all, the resources themselves are very limited in rural areas. The teachers also think that the effectiveness of reading habits resulting from this program is far behind students' achievement in urban areas.

Finally, parents and teachers in rural areas feel presented with no clear guidelines or reference sources for building students' reading habits. In rural areas, parents are not significantly exposed to education development, and they are in dire need of guidance in implementing activities such as reading. These findings confirm a study by Jafre Zainol Abidin, Pour Mohammadi, and Choon Lean that changes in students' reading habits and society create a need to explore new studies that must also occur in Malaysia. ${ }^{35}$ Excellent and beneficial cooperation can also be established between parents and the school if they are given clear guidelines and reference sources.

\section{CONCLUSION}

Conclusions based on the results of interviews and statements made by study participants consisting of teachers, school leaders, and parents in urban and rural areas found that their issues were almost the same in both location categories. The issues stated demand an effective solution to students' reading habits to resolve the issues faced. This is because some of the issues mentioned involve issues and challenges that need to be addressed by stakeholders such as schools, teachers, communities, and parents based on information from the findings of issues of the reading habits of Malaysian students.

\section{REFERENCES}

Annamalai, S., \& Muniandy, Reading Habit and Attitude among Malaysian Polytechnic Students. International Online Journal of Educational Sciences, 5(1), 2013

Banou, C., Kostagiolas, P. A, \& Olenoglou. The reading behavioral patterns of the Ionian University graduate students: Reading policy of the Greek academic libraries. Library Management, 2008

Bashir, I., \& Mattoo, N. H. A study on study habits and academic performance among adolescents (14-19) years. (International Journal of Social Science Tomorrow, 1(5), 2012,

Chotitham, S., \& Wongwanich, S. The Reading Attitude Measurement for Enhancing Elementary School Students ' Achievement. Procedia Social and Behavioral Sciences, 2014

Clark, C., \& Hawkins, Young people's reading: The importance of home environment and family support: More findings our national survey (London: National Literacy Trust., 2018)

Cohen, L., Manion, L., \& Morrison, K. Research method in education (5th.). London: Routledge Palmer, 2000

Creswell, J. W. Educational research: Planning, conducting, and evaluating quantitative and qualitative research (3rd ed.). New Jersey: Pearson Prentice Hall, 2008

Patton, M.Q. Qualitative research and evaluation methods (2nd ed.). Newbury Park, CA: Sage, 1990 
Erdem, A Research on Reading Habits of University Students: (Sample of Ankara University and Erciyes University). Procedia - Social and Behavioral Sciences, 174, 2015

Kvale, S. Doing interviews. Sage, 2008

Holland, M. (2002). Analyzing and interpreting the data. Dalam $C$. Daymond dan I. Holloway. Qualitative Research Methods in Public Relations and Marketing Communications, 2002

Inderjit, S., Reading Trends and Improving Reading Skills among Students in Malaysia. International Journal of Research In Social Sciences, 3(5), 2014

Jafre Zainol Abidin, M., PourMohammadi, M., \& Choon Lean, 0. The Reading Habits of Malaysian Chinese University Students. Journal of Studies in Education, 1(1), 2011

Judith Nesamalar Tharumaraj \& Nooreen Noordi, Analysing teachers' reading reading reading habits and teaching strategies for reading skills. Malaysian Journal of ELT Research, 7 (1), 2011

Kamalova \& Koletvinova, The problem of reading and reading culture improvement of students-bachelors of elementary education in modern high institution. International Journal of Environmental and Science Education, 11(4), 2016

Kementerian Pendidikan Malaysia, Laporan Tahunan 2017 Pelan Pembangunan Pendidikan Malaysia 2013-2025, 2018

Kementerian Pendidikan Malaysia, PISA 2015: programme for international student assessment, 2016

Kutay, V. A survey of the reading habits of Turkish high school students and an examination of the efforts to encourage them to read. Loughborough University,2018.

Lau, K. Within-year changes in Chinese secondary school students ' perceived reading instruction and intrinsic reading motivation, 2014

Loh, C. E. Building a Reading Culture in a Singapore School: Identifying Spaces for Change Through a Socio-spatial Approach. Changing English: Studies in Culture and Education, 22(2), 2015

Miles, M. B., \& Huberman, Qualitative data analysis: An expanded sourcebook (2nd ed.). Thousand Oaks: Sage Publications, 1994

Mohamad. Amin Embi, \& Nordin, Determining e-Portfolio Elements in Learning Process Using Fuzzy Delphi Analysis. International Education Studies, 8(9), 2015

Mujan Yusuf, K., Sigan John, D., Dawn Kundrata, K., \& Pandian, (2019). Value and Self-Concept: A Study on Reading Habits among Primary School Students in Sarawak. International Journal of Asian Social Science, 9(12), 2019

Najeemah Mohd Yusof, Influence of family factors on reading habits and interest among level 2 pupils in national primary schools in Malaysia. Procedia-Social and Behavioral Sciences, 5, 2010.

Obada, A. M. Reading culture in Nigeria: A librarian's perspective. Ondo: Covena House Publishers, 2019

Olasehinde, Akanmode, Alaiyemola, \& Babatunde, Promoting the reading culture towards human capital and global development. English Language Teaching, 8(6), 2015

Onwuegbuzie, A. J., \& Collins. A typology of mixed methods sampling designs in social science research. The Qualitative Report, 12 (2), 2007

Pandian, Mikal, E., \& Dawn Kundrata, Reading with Mom: Reading Habits among Rural Readers in Sarawak. International Journal of Asian Social Science, 10(1), 2020 
Yin, R.K. Case study research: Design and methods $\left(3^{r d}\right)$. Newburry Park, CA: Sage, 2014

Holland, M. Analysing and interpreting the data. Dalam C. Daymond dan I. Holloway. Qualitative Research Methods in Public Relations and Marketing Communications, 2002
Zuridah Hanim Akhir, Mohd Hasani Dali, \& Khaliza Saidin. Faktor yang mempengaruhi peranan pengetua dalam meningkatkan amalan membaca menerusi program NILAM. Journal of Advanced Research in Social and Behavioural Sciences Journal, 1(1), 2017 